\title{
Methods of Developing of the Prospective Teacher's Creativity
}

\author{
Ospanova B. A. ${ }^{1}$, Redlikh S. M. ${ }^{2}$, Sagdullaev I. I. ${ }^{1}$, Tashbulatova A. E. ${ }^{1}$, Abdulhakov A. B. ${ }^{1}$ \& Dadashov D. T. ${ }^{1}$ \\ ${ }^{1}$ H. A. Yasawi International Kazakh-Turkish University, B. Sattarkhanov Avenue 29, Turkistan, the main campus, \\ Kazakhstan \\ ${ }^{2}$ Kuzbass State Academy, Novokuznetsk, Russian Federation \\ Correspondence: Ospanova B. A., H. A. Yasawi International Kazakh-Turkish University, B. Sattarkhanov \\ Avenue 29, 161200 Turkistan, the main campus, Kazakhstan. E-mail: ibragim.sagdullaev@mail.ru; \\ ibrokhim.sagdullaev@iktu.kz
}

Received: January 11, 2015 Accepted: April 2, 2015 Online Published: May 16, 2015

doi:10.5539/ass.v11n13p310 URL: http://dx.doi.org/10.5539/ass.v11n13p310

\begin{abstract}
In the modern conditions, the demand for creative and creative-competitive personality is extremely large, and it will continue to increase. Therefore, the importance of the orientation of professional education at the comprehensive promotion of creative self-development of a competitive person does not raise doubts. In this article, the authors generalize their long-term experience in high school to form a creative personality of students as future professionals in demand in the new market conditions of competition. The technology of formation of creativity of future expert and results of skilled and pedagogical work on development of creative potential of students in higher education institution to professional creative self-development of future professional activity are presented.
\end{abstract}

Keywords: creativity, creation, creative personality, creative thinking, creative readiness, reflection, and professional self-development

\section{Introduction}

The driving forces of innovation processes in higher education in Kazakhstan, are adapting to the internal labor market and at the same time striving to enter the global educational system as a full member. Continuous adaptation of educational programs to market demand of work is necessary. In performance criterion laid readiness for practical activities and real competitive graduates.

Therefore, the education system of the Republic of Kazakhstan should be focused primarily on providing highquality training and education of students, preparing them for the labor market in the new competitive environment. At the same time, in the labor market there is a demand for professionals with creative thinking.

In this context, the system of higher education in modern conditions it is necessary to give a new quality of social status and an understanding of it as a special sphere, the primary objective is to advance training of creative, professional and mobile professionals. Methods of teaching the student, the teacher equips its ability to acquire knowledge, learn, work and be able to live and to live together with other people. It is defined as the fundamental purpose of education in UNESCO documents.

With the increasing role of personality factors in solving economic and social problems there become particularly urgent need for the future specialists integral way of thinking, that is, the ability to observe and analyze the facts and phenomena, to think creatively and professionally competent to take decisions.

The modern job-oriented technology of training students suggests the need to consider how the general laws of formation of the personality and the individual characteristics of students, the development of each of these individual abilities, interests and aptitudes. This approach to learning, seems to have become particularly relevant in the circumstances to make headway variable education.

The development and formation of creativity and creative thinking more fully disclosed in the research of psychologists. So, S. L. Rubinstein, B. M. Teplov, M. G. Yaroshevskiy, B. M. Kedrov, A. M. Matyushkin, I. A. Ponomarev, A. N. Luk, A. V. Brushlinskiy, and others considered the relationship properties of the human psyche and its activities, the mechanisms of creativity as a unity of productive and reproductive side of mental activity. In the context of psychological abilities of the individual performed the works of B. G. Anan, N. D. Levitov, N. S. 
Leites, V. D. Shadrikov and others. Problems of development of the creative potential of the individual and the motivational sphere of creative activity covered in the studies of A. M. Melik-Pashayev, Y. Poluyanova, L. I. Bozovic, A. N. Leontiev's and others.

Much attention is paid to the development of creative personality traits also in the works of foreign scholars as (Gilford, Barron, Mednick, Smith, Taylor, Torrance, Trik, \& Wallach, etc.).

In recent years a number of studies that traced a comprehensive approach to creativity with the positions of the various fields of science, attempts to create a paradigm of Creative Education (Vishnyakova, etc.).

M. M. Zinovkina for the first time identified the methodological foundations of creative holistic educational system of continuous creative thinking (CCT) at all levels of education. In particular, the concept developed in detail, methods, tools and pedagogical conditions of creative systems, training, focused on the formation of a system of creative thinking among university students. A number of studies (Zinovkina, Medakova, Passover, \& Esaulov, etc.) draw attention to the fact that the success of creative thinking in the process of professional education largely depends on the level of formation the main components of creative thinking in the earlier stages of identity formation.

The Kazakhstan teachers, as well as their colleagues around the world, responding to the challenges of the XXI century, are actively searching for the original approaches to the organization and development of the education system on a new methodological platform, the essence of which is to create conditions for students to get in educational institutions "effective knowledge", that is, knowledge, abilities, skills, experience, the competences necessary in an everyday life, for the solution of real problems of the present.

There are scientific studies on this problem in our country: the formation of a creative personality high school students in the process of verbal and cognitive activity (Zhetpisbaeva), to improve readiness of the future teachers for professional creative activity (Iljasov), the definition of pedagogical conditions of formation of creative abilities of students (Kenzhebaeva), the formation of creativity of future professionals in the university system (Ospanova), etc.

The collection conducted psychological and educational research provides a solid theoretical and practical basis for a general theory of creativity.

Without belittling the importance above designated concepts, we note that the complex scientific and pedagogical support of the process of formation of creativity in the university education system is not yet fully take into account new trends in training (integration of professions, subjectivity, reflection, synergy, expertise, creative innovation education, the intensification new educational technologies, co-creation), which hinders the development of the theory of creativity and the possibility of its implementation in the training of future specialists.

\section{Materials and Methods}

The study applied the methods of study and analysis of the philosophical, psychological and educational research on creativity and individual creativity, analysis and monographic dissertation research on the theory of creativity, analysis of theoretical and pedagogical, didactic, methodical work on the creativity of the individual and enhance its professional competence, the study and compilation of teaching experience, the study of creative activities of university students, observation, interview and conversation with the subjects of the educational process, and analysis of university documents (classifier, SES, curricula, model curricula, textbooks, teaching facilities, etc.), questioning the various categories participants in the educational process of the university, student self-assessment of their creativity, expert assessment of the effectiveness of creative activities, conducting research and teaching work, methods of statistical analysis, etc.

\section{Results}

Education, focused on personal development, achieves its goals in such a degree that creates a situation of demand for the individual, its power of self-development. Self-development is a creative attitude of the individual to himself, his creation of the self in the process of active influence on the outer and inner world, with a view to transforming them.

Any most advanced methods of teaching the subject can be updated only by the high professionalism of the teacher, that is, the presence of the teacher specific personal and professional qualities.

The content development and pedagogical work consisted of several stages.

Stage 1 - the communicative phase. This stage includes a professionally -semantic dialogue, where the joint selection of topics for discussion, is the nomination of topical issues, followed by a reflection of the dialogue, 
which requires a deep personal experience of the teacher and the activity and organize personal and psychological, organizational, and activity-related resources.

Stage 2 - active- search activity. During the realization of active and search model of formation of creativity, together with the teacher the learners project any professional mediated situation connected with the maintenance of the studied subject or future activity, and then work on the contradictions independently inherent in it.

At this stage the organization of independent and research work of students, including the preparation of various reports, research reports, etc.is significant.

Stage 3 - activity- practical stage of formation of creativity is focused on the use of structural and role-playing, problem- role-playing games. In this case, the maximum activated processes of personal identification, development and learning needs of all students as it encourages the subject of the educational process for independent, enterprising and creative solutions. Also, this stage involves the use of the solutions arising spontaneously or specially organized professionally designed and practical situations.

Stage 4 - reflective. Formation of creativity aimed at reflection, through self-knowledge and self-esteem, it involves the use of the formulation and solution of the future specialists reflexive and situational problems. A distinctive feature of this stage is its intimate character, which is realized in the form of compositions, essays, etc.

Stage 5 - the stage of professional self-development, aiming at becoming creative sense of competence of the future specialist. At this stage the ability as personal responsibility for the made decisions, for development and strategy implementation is formed.. This is the final stage, summarizes and consolidates the results of all previous stages and marks the transition from the process of development of the creative potential of students in high school to the professional creative self-development of future professional activity.

Empowering the learning process in the formation of future professionals in the creative person requires a restructuring of all its components, and, above all, educational purposes. As part of the learning objectives must be designed mastery of knowledge, skills, and mastery of creative solutions to the problem of educational and professional activities, in unity with the creative development of the individual, its values, motivation, skills and motivation of other properties. System of such purposes we have identified as an aspect of creative readiness of students for professional work.

More than 800 characteristics of the students, the separate fortune of the personality come into as a result of studying, their manifestations in educational and extracurricular activities were analysed. The obtained data show that nature of assimilation by students of the same concrete section of pedagogical disciplines can actualize various properties of the personality and qualitative distinctions of their manifestation.

Special significance in experimental work was given during the analysis of various professional atypical situations. At this stage, the students studied the scheme of analysis of psychological and educational and occupational situations. The students were offered two types of situations: it is necessary to choose a professional and pedagogical decision or evaluate proposed.

In the first case, the analysis must begin with a description of the image of the situation and the allocation of common-sense knowledge that can be applied to solve it. The necessity of such a step due to the fact that students often take some action in the situation just based on common sense and momentary emotions and ignores scientific knowledge. And it is not always understood: the student may assume that served as the basis for its action is scientific knowledge.

The next step - the scientific analysis of the situation, the choice of the scientific knowledge (educational, psychological, sociological, etc.) that can be applied to analyze the situation.

Next, you need a comparison of conventional and scientific knowledge, the resolution of conflicts between them.

The next step - to relate this situation with a model and identify its specific, distinctive moments. As a rule, in teaching practice often similar situations, but each of them unique. It is therefore important to assess how the stereotype solutions typical situation is applicable to the existing conditions.

The results of the stages of cognitive schema are the model of the situation, the construction of which allows you to go to a model solution to the situation. Its construction includes the steps of cognitive schema: forecasting further development of the situation; possible choice -making and assessment of their impact; definition of the alleged psychological and educational barriers that impede action in a given situation, and how to overcome them; description of possible erroneous actions and ways to prevent them; (play) the situation in different 
positions. For this purpose, each student group sessions were conducted in the form of collective thinking activity (7-8 people in a subgroup). The task of the work - to play learning activities for the previous semester, analysis, identification of difficulties, the search for the causes and ways to improve.

This activity allows you to create the ability to listen to each other, to perceive and understand the information, ask questions in the understanding, to clarify, to make critical comments, and to give advice.

Each subgroup of students accumulate material, which is registered as a message. The organizer of communication constantly stimulates the expression of mental activity.

In the end, the process of collective thinking activity students form, above all, a clear idea of reflection. Reviewing and analyzing the content of the different interpretations of this phenomenon, the students have come to the following terms "reflection - this is a perfect reproduction of the purpose of its analysis, critique, its reformation and improvement."

An important characteristic of reflective regulation is applied stability test means and methods of realization. This follows from the definition of reflection, according to which the reflexive system is characterized by not only the formation process, but also its subsequent application in solving similar problems. Making the final compilation of the results obtained, it should first of all be noted that the figures obtained levels of creativity change under the influence of a reflexive mechanism. In the process of organizing relations between the specific situation of communication and personal worldview, which include a presentation about human relationships and the idea of the self, the subject chooses a particular principle, which gives a general plan for solving any problem situation and cognitive. There is a self-mobilization and self-organization of the subject in a problem situation in its resolution. The mechanism associated with the re-interpretation of reflection, change of personal relation of the subject to his or her own way he assumes to be successful in solving non-standard tasks.

The following activities are a logical continuation of the previous ones: the students were asked to carry out a reflection subgroups of his or her career in the industrial practice. In the course of reflection, the students visited different roles and activities that they carried out in the course of practice. Analyzed their difficulties and shortcomings.

Formation of abilities and skills of effective social behavior, optimizing communications capabilities determine the development of strategic, prioritized properties competitiveness.

To solve the problems, we used the following diagnostic methods: the "unfinished sentences ", individual advice, tests - questionnaires.

For example, using projective techniques "unfinished sentence" we have identified motivational and meaningful education, time perspectives, and the objects of self-improvement.

According to the students' surveyed professionals, describes the empirical freedom (57\%), innovation, or the author's ideas, the implementation (63\%), a tireless intellectual curiosity (36\%), learning throughout life (22\%). Ranking qualities associated with creative professionals has the following sequence:

1 st place - the ability to create new and original ideas;

2nd place - a large number of ideas in a unit of time;

3rd place - the nomination of unique ideas per unit of time (originality);

4th place - offer recurring ideas in the unit of time (flexibility);

5 th place - the originality of Use.

The data show that from the second to the fourth course increases the percentage of students who believe that in the learning process to make more use of computers, introduce new and update existing training courses based on the views of students. Naturally, the fourth year students are more interested in improving the practice of the specialty.

Analysis of the data suggests that the students of the first and second year, signs of reproductive level of creativity $(46.7 \%)$. This is due to the fact that the purpose of the reproductive activity is the formation of a variety of socio- normative behaviors, skills and habits and their underlying systems. Reproductive level involves the assimilation of knowledge and willing to play the sample. This is why the freshmen found a large number of students using the action role models and literal application of the assimilated algorithm (40\%).

Third-year students showed a level of ownership of productive techniques of creativity (33.3\%). This level of the students showed a predominance of novelty items, atypical and opening fundamentally new or improvement of the old. That is why the subjects did not have any ready answer to the question, nor the finished scheme to get an 
answer. In the normal course of business or assimilated earlier algorithm adapted to the new situation, or recreated from parts of several algorithms (36.7\%).

Creativity techniques were used in the vast majority of fourth-year students $(63.3 \%)$. Creativity in these students was described the creation of new values, new ways to transform reality in the generation of images, generalizations, goals, meaning, motives and interests. Subjects were identified semantic orientations on creativity and creativity, the ability to overcome obstacles, to act not only according to the known stereotypes, but also with regard to unique situations, especially material (76.7\%).

Dynamics of formation of the components of creativity in the experimental group are presented in the figure below.

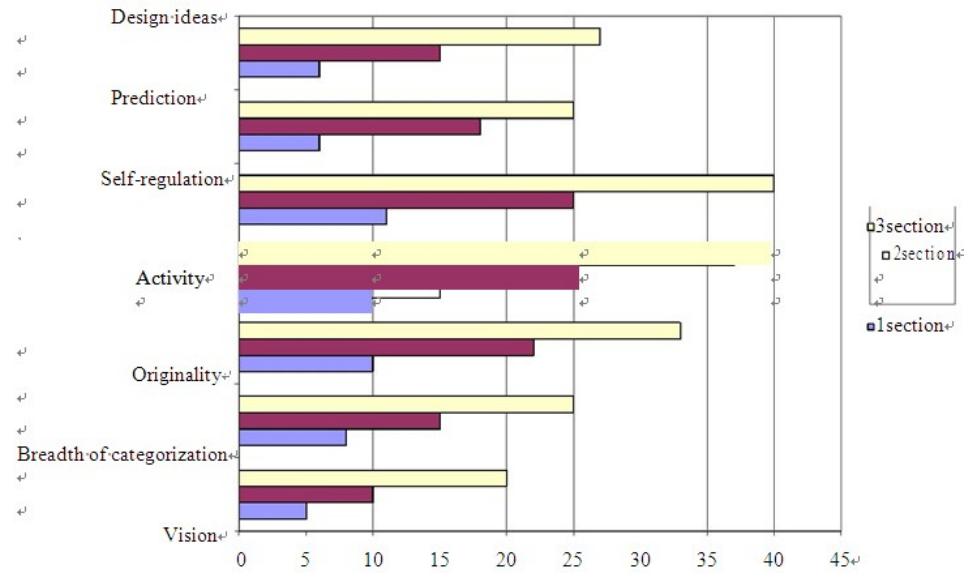

Figure 1. The dynamics of the component "activity-base of the creativity"

\section{Discussions}

Analysis of the results of training activities carried out in (experimental" and "control) groups showed that the subjects revealed is significantly different. For students of the experimental group is characterized by taking the initiative, self-reliance, the use of a large number of sources, attention to controversial issues, the desire to present the main points of view. At classes of students from both groups were asked to compile a report, from their point of view, an interesting and relevant topic in psychology. Students from the experimental group took interest in the problem and asked questions. Students in the control group showed no special interest. In other words, in the initial phase difference between the observed motivation. Therefore, the report prepared by the student in the experimental group, caused a lively discussion of the dispute. The student in this case, too, was very active, even in the discussion expressed original ideas. The characteristic features of the control group included: the desire to avoid work, passivity, lack of autonomy, the use of the preparation of the report or a textbook, at best, 1-2 additional literature, short and dry discussion, no problems, discussion of findings and proposals. The reaction to remarks of fellow students depended on individual and psychological features, the positions were not defended and proved, sometimes even under the influence of statements of fellow students they were refused.

Creative tasks have been developed on the basis of tests Torrance-Gilford. For students of the experimental group is characterized by the use of a large number of classes of phenomena (flexibility), wide associative relationships, the desire to go beyond the instructions, originality of answers, the creative direction of the work. The results of this group for all parameters were significantly higher than the results of the opposing control group.

In solving the psychological and pedagogical problems the students of the experimental group formed different types of productive thinking steps: forming the goal, planning, evaluation, etc. The analysis, comparison, and selection were carried out mainly on their new, original criteria.

Solutions differed with novelty, surprise and originality. Students of the control group suggested, usual, template, stereotyped, easily predictable solutions. These results emphasize the focus on the implementation of productive mental actions in the subjects of the experimental group.

The study found that the experimental group leading motives are cognitive. Manifestation of the strongest links 
between the motives was the motives: cognitive - professional, informative - personally prestigious. The students of the control group leading motives: social identity - professional, social identification - cognitive. Students of the experimental group showed the desire not only to learn something new, but also to learn it independently, focus on the transformation of their own activity, that is, the manifestation of creative motivation. Also revealed levels of creative motivation: stable and unstable. For students with a sustainable level of motivation is characterized by the pursuit of creative activity and in terms of academic work, and in the conditions of the experiment. For students with unsustainable levels of creative motivation manifestation of creative possibilities took place in fixed when solving some complex tasks, or the introduction of a strong external stimulus. The development of a certain level of creative motivation is the result of peculiarities of the relationship between the motifs in the structure of motivation.

During the classes in psychology for one semester (as psychology departments at non psychological is only one semester), we have created the conditions of joint productive activity. The aim was to check how this situation has an impact on the development of creative motivation.

The content of pedagogy objectively the role of culture- opening functions of school and education, humanist aspects of the profession of the future specialist. The idea of a modern course in pedagogy for teaching - the identity of the modern student.

Thus, instead of the non-personal, abstract pedagogy which was taught until recently in higher education institutions, there come personality- oriented discipline in which the central place is occupied by the personality of the student, teacher personality, the personality of the scientist -teacher. This allows to stimulate the leading teacher for identification of the problem in the new conditions -, the knowledge and the development of individual tendencies and characteristics of students, creating favorable conditions for the development of all essential for individuals and their self-development.

\section{References}

Barron, F. (1988). Putting creativity to work. In R. Sternberg, \& T. Tardif (Eds.), The nature of creativity (p. 255). Cambridge Press.

Csikszentmihalyi, M. (1997). Creativity. Flow and the psychology of discover and invention (p. 325). N.Y.: Harper Perennial.

Eysenck, H. J. (1995). The natural history of creativity (p. 295). Cambridge: Camb. Univ. Press. http://dx.doi. org/10.1017/CBO9780511752247

Feldman, D. Y., \& Gardner, H. (1994). Changing the world: A framework for the study of creative (p. 305). Yale: Yale Press.

Ilyasov, N. (1986). Research and teaching fundamentals to improve readiness of the future teachers for professional creative work: Diss. Of Candidate. ped. Science. Almaty (p. 155).

Ospanova, B. A. (2010). Modern priorities of higher education of Kazakhstan in globalization and integration context. International scientific conference. Pedagogical theory of integrative function in the world educational domain (Vol. 2, pp. 197-200). Helsinki.

Ospanova, B. A. (2012a). Creative psychology: a textbook for PhD doctoral students. Almaty (p. 420).

Ospanova, B. A. (2012b). Pedagogical theory integrative function in the world educational domain International scientific conference (Vol. 1, pp. 371-375).

Ospanova, B. A. (2013). Theory and technology of formation of creativity of the future specialist (p. 305). Monography. Germany.

Shadrikov, V. D. (1993). Philosophy of education and educational policy (p. 181).

Sternberg, R. J. (1988). In R. Sternberg, \& T. Tardif (Eds.), A three-facet model of creativity (p. 147).

Vishnjakova, N. F. (1995). Creative psychopedagogy (p. 157). Minsk.

Yermolayeva, L. B. (2003). Psychology of art (p. 304). Moscow: Academic Project.

Zhetpisbaeva, B. A. (2003). Formation of the creative person senior pupils in the verbal-cognitive activity: Diss.of Candidate. Of ped. Science. Almaty (p. 152).

Zinovkina, M. (1999). Creative technology education. Higher Education in Russia (p. 104).

\section{Copyrights}

Copyright for this article is retained by the author(s), with first publication rights granted to the journal.

This is an open-access article distributed under the terms and conditions of the Creative Commons Attribution license (http://creativecommons.org/licenses/by/3.0/). 